\title{
Trans fatty acids in the Scottish diet
}

An assessment using a semi-quantitative food-frequency questionnaire*

\author{
BY C. BOLTON-SMITH ${ }^{1}$, M. WOODWARD ${ }^{2}$, S. FENTON ${ }^{1}$, M.-K. MCCLUSKEY ${ }^{1}$ \\ AND THE LATE C. A. BROWN ${ }^{1}$ \\ ' Cardiovascular Epidemiology Unit, University of Dundee, Ninewells Hospital and Medical School, \\ Dundee DDI $9 S Y$ \\ ${ }^{2}$ Department of Applied Statistics, Harry Pitt Building, University of Reading, Whiteknights Road, \\ PO Box 240, Reading RG6 2FN
}

(Received 22 December 1994 - Revised 16 February 1995-Accepted 2 March 1995)

Trans fatty acids produced during hardening of oils have been associated with higher cholesterol levels and increased risk of heart disease. The potential risk from trans fatty acids may be greater in populations with relatively low intakes of essential fatty acids such as the Scots, who also have a high prevalence of heart disease. Means and ranges of trans fatty acid intakes are reported here for a Scottish population. A semi-quantitative food-frequency questionnaire was used to survey the diet of 10359 Scottish men and women aged 40-59 years in 1984-6 as part of the baseline Scottish Heart Health Study. Trans fatty acid levels were calculated for each food item on the questionnaire and the total subdivided into that which is derived naturally (primarily by bacterial fermentation in ruminants) and that which is produced during industrial hydrogenation (hardening) of vegetable and fish oils. Means and ranges of intakes of each trans fatty acid variable were calculated by sex, age, smoking and social class groups. Mean total trans fatty acid intakes for men were 7.1 (SD 3.1) g/d, 2.7 (SD 2.9) \% energy and for women were 6.4 (SD 2.9) g/d, 3.3 (SD 3.0) \% energy. Industrially hydrogenated trans fatty acids made up nearly $58 \%$ of the total intake for men and $61 \%$ for women, with about $60 \%$ coming from cakes, biscuits and sweets, and $20 \%$ coming from the cheaper hard margarines. The main sources of the naturally derived trans fatty acids were red meat $(27 \%)$, milk $(20 \%)$, butter (18-19\%) and cheese (13-16\%). Differences between age, smoking and social class groups were apparent. However, apart from the social class differences of up to $1 \mathrm{~g} / \mathrm{d}$, these were so small that they are unlikely to be of any biological significance unless compounded by other factors such as marginal essential fatty acid adequacy. The possibility of trans fatty acid intakes up to $48 \mathrm{~g} / \mathrm{d}$ and $12 \%$ total energy (compared with the Department of Health (1991) recommendations of $5 \mathrm{~g} / \mathrm{d}$ or $2 \%$ energy) highlights the need for careful monitoring of the health risks at these high levels of intake.

Trans fatty acids: Margarine: Food-frequency questionnaire: Social class

Recent reports on the effects of dietary trans fatty acids (tFA) on blood lipid levels (Mensink \& Katan, 1990; Troisi et al. 1992; Lichtenstein et al. 1993; Judd et al. 1994) and coronary risk in the USA (Willett et al. 1993; Ascherio et al. 1994) have fuelled new interest in tFA in relation to health. Before this resurgence in tFA-related research, the stance of government and health organizations has been that the evidence against tFA has been insufficient to merit warnings of health detriment to the general population (Federation of American Societies for Experimental Biology, 1985; British Nutrition Foundation, 1987). Recommendations for upper limits have nevertheless been set (Department of Health, 1991; Scottish Office, Home and Health Department, 1993).

* Dedicated to the fond memory of Dr Colin Andrew Brown: an outstanding scientist. 
Since the mid 1950s when saturated fats were linked with CHD risk, margarine manufacturers have preferred to use hydrogenated vegetable and fish oils rather than naturally hard (high saturated fat) animal fat to provide the firmness and texture of their products. This has meant that the tFA content of margarines has in general been greater than that of natural products such as butter and lard.

Functionally it may be important to differentiate between naturally occurring tFA in meat and dairy products (mainly trans-11 C18:1, vaccenic acid derived from bacterial fermentation in the rumen) and $\mathrm{tFA}$ which are produced as a result of hydrogenation (hardening) of liquid vegetable (mainly trans-9 C18:1, elaidic acid) and fish oils (trans isomers of $\mathrm{C} 18: 1$ to $\mathrm{C} 24: 1$ ) (Peacock \& Wahle, 1988; Willett et al. 1993). Specifically, elaidic acid may interfere with essential fatty acid metabolism, such that people with only a marginally adequate linoleate intake may be at greater risk of ill effects from tFA (Wahle \& James, 1993). The Scots, who are renowned for their high prevalence of CHD, may have a high risk of CHD due to low intakes of linoleic acid (Reimersma et al. 1986; Wahle et al. 1991; Bolton-Smith et al. 1992a), and so may also be particularly susceptible to tFA in their diet.

Reports on tFA intakes in UK populations are sparse: an assessment of tFA was made in the Dietary and Nutritional Survey of British Adults (Gregory et al. 1990), but little difference was revealed between population subgroups. Since information on fat type, meat and dairy product consumption was available as part of the semi-quantitative foodfrequency questionnaire data-set from the Scottish Heart Health Study (SHHS), it was both pertinent and possible to make an assessment of usual intakes of tFA in middle-aged Scottish men and women and to investigate differences between social and lifestyle groups. Values for total, natural hydrogenation (primarily ruminant) and industrial hydrogenationderived tFA are reported here and these are compared with the current recommendations and previously reported values.

\section{SUBJECTS AND METHODS}

The subjects were 10359 men and women aged $40-59$ years who participated in the Scottish Heart Health Study between 1984 and 1986. These people were recruited from general practitioner registers across Scotland in a cross-sectional manner in 5-year age-stratified bands. Health and socio-demographic details were elicited by questionnaire and a blood sample and body measurements were obtained at a clinic visit. The overall response rate was $74 \%$ (excluding Post Office returns) after one reminder letter. The full recruitment details and study protocol have been reported previously (Smith et al. 1989).

Diet was assessed by a validated semi-quantitative food-frequency questionnaire (FFQ) (Bolton-Smith et al. $1991 c, b$ for the macronutrients and antioxidant vitamins respectively, and Bolton-Smith et al. $1992 b$ for linoleic acid). Specific validation of the FFQ for tFA intake was not possible since the adipose tissue fatty acid analysis did not include trans isomers. The FFQ consisted of sixty questions on the usual frequency of consumption of foods/food groups and family consumption of fats, cheese, milk and sugar. The frequency options were 1-7 d/week, fortnightly, and rarely or never. Alcohol intake was determined by a $7 \mathrm{~d}$ recall question.

tFA levels were assigned to the food or food groups used in the FFQ based on values from a variety of sources, including the Ministry of Agriculture, Fisheries and Food (MAFF), literature values and 'confidential' product information from industry. Since the survey was carried out in the mid 1980s, care was taken to use tFA values obtained from food analysis at that time, as far as was possible. Total tFA values were subdivided into naturally occurring (N-tFA) or industrial hydrogenation-derived (H-tFA) fat. Thus N-tFA included the naturally occurring tFA in ruminant meat and meat products, lard, butter and dairy produce as well as the tFA reported to be in fish, poultry, eggs and potatoes. H-tFA 
Table 1. Intakes of trans fatty acids for men and women in Scotland

(Mean values, standard deviations and ranges)

\begin{tabular}{|c|c|c|c|c|c|c|}
\hline & \multicolumn{3}{|c|}{ Men } & \multicolumn{3}{|c|}{ Women } \\
\hline & Mean & SD & Range & Mean & SD & Range \\
\hline \multicolumn{7}{|l|}{ Total } \\
\hline$(\mathrm{g} / \mathrm{d})$ & $7 \cdot 1$ & $3 \cdot 1$ & $0 \cdot 8-33 \cdot 7$ & 6.4 & $2 \cdot 9$ & $0.4-47.6$ \\
\hline (\% En) & $2 \cdot 7$ & 0.9 & $0.45-11.6$ & $3 \cdot 3$ & $1 \cdot 1$ & $0.33-11.6$ \\
\hline (\% Fat $)$ & 7.8 & $2 \cdot 1$ & $2 \cdot 8-21 \cdot 5$ & $8 \cdot 2$ & $2 \cdot 3$ & $1 \cdot 2-22 \cdot 4$ \\
\hline \multicolumn{7}{|l|}{$\mathbf{N}$-tFA } \\
\hline$(\mathrm{g} / \mathrm{d})$ & $2 \cdot 9$ & $1 \cdot 3$ & $0-11.4$ & 2.5 & $1 \cdot 1$ & $0-9 \cdot 1$ \\
\hline (\% En) & $1 \cdot 1$ & 0.4 & $0-3 \cdot 0$ & 1.3 & 0.5 & $0-3 \cdot 4$ \\
\hline (\% Fat) & $3 \cdot 2$ & 0.9 & $0-6 \cdot 4$ & $3 \cdot 2$ & 0.9 & $0-5 \cdot 6$ \\
\hline \multicolumn{7}{|l|}{ H-tFA } \\
\hline$(\mathrm{g} / \mathrm{d})$ & $4 \cdot 2$ & $3 \cdot 0$ & $0 \cdot 2-24 \cdot 6$ & 3.9 & $2 \cdot 8$ & $0 \cdot 2-44 \cdot 0$ \\
\hline (\% En) & 1.6 & 0.1 & $0 \cdot 2-10 \cdot 4$ & 1.9 & 1.2 & $0.2-10.8$ \\
\hline (\% Fat) & $4 \cdot 6$ & $2 \cdot 7$ & $0 \cdot 5-20 \cdot 6$ & $5 \cdot 0$ & 2.9 & $0.5-21.0$ \\
\hline
\end{tabular}

Total, total trans fatty acids; N-tFA, natural sources of trans fatty acids (primarily ruminant); H-tFA, trans fatty acids formed during hydrogenation of oils; $\% \mathrm{En}$, percentage of total energy intake, inclusive of alcohol; $\%$ Fat, percentage of total fat intake.

included the tFA occurring naturally and as a result of hydrogenation of vegetable and fish oils used in household and commercial margarines and oils for spreading, cooking and baking. No detailed information was available from the FFQ regarding the proportion of cooking oil which was reused in deep frying. It was therefore necessary to set a value $(10 \%$ of the total oil consumed) and assign to this an appropriate tFA level of $35 \%$ of total fat. The tFA values were integrated into the FFQ analysis programme which used the McCance and Widdowson food composition tables (Paul \& Southgate, 1978) and appropriate updates of the time. (The precise tFA values set for each item on the FFQ are available from the authors.)

Of the 10359 men and women who participated in the SHHS, 164 were excluded from the sub-population analyses of tFA intake due to missing information regarding the type of spreading fat or cooking oil used. These people were otherwise representative of the whole population (i.e. they did not belong to any one particular subgroup).

\section{Statistical analysis}

The mean and standard deviation for tFA intakes $(\mathrm{g} / \mathrm{d}$ and percentage of total dietary energy) are reported by sex and 5-year age group, smoking habit (current, ex-, never smokers) and occupational social class (non-manual I-IIIN; manual IIIM-V; Office of Population Censuses and Surveys, 1980). Women were classified according to their husbands' occupation if pertinent, or otherwise by their own occupation. The classification of the unemployed and retired was based on their last previous employment. Spearman rank correlation coefficients were determined between tFA intake and dietary total, saturated and polyunsaturated fat (all as $\mathrm{g} / \mathrm{d}$ ). Skewed distributions of intakes were normalized (by logarithm and square root transformation) before ANOVA to detect significant differences between the population subgroups. The untransformed values are reported in the tables and figures.

\section{RESULTS}

Table 1 gives the mean and range of tFA intake for men and women. The 5th and 95th percentiles for total tFA were $3.3 \mathrm{~g} / \mathrm{d}(1.5 \%$ energy) and $12.7 \mathrm{~g} / \mathrm{d}$ ( $4.3 \%$ energy) for men, 
Table 2. Trans fatty acid intake by age group in Scottish adults (Mean values and standard deviations)

\begin{tabular}{|c|c|c|c|c|c|c|c|c|c|c|}
\hline \multirow[b]{2}{*}{$\begin{array}{l}\text { Age (years)... } \\
n \ldots\end{array}$} & \multicolumn{5}{|c|}{ Men } & \multicolumn{5}{|c|}{ Women } \\
\hline & $\begin{array}{c}40-44 \\
1223\end{array}$ & $\begin{array}{c}45-49 \\
1172\end{array}$ & $\begin{array}{c}50-54 \\
1328\end{array}$ & $\begin{array}{c}55-59 \\
1250\end{array}$ & $P \dagger$ & $\begin{array}{c}40-44 \\
1330\end{array}$ & $\begin{array}{c}45-49 \\
1251\end{array}$ & $\begin{array}{c}50-54 \\
1327\end{array}$ & $\begin{array}{c}55-59 \\
1262\end{array}$ & $P \dagger$ \\
\hline \multicolumn{11}{|l|}{$g / d$} \\
\hline $\begin{array}{l}\text { Total } \\
\text { (SD) } \\
\text { N-tFA } \\
\text { (SD) } \\
\text { H-tFA } \\
\text { (SD) }\end{array}$ & $\begin{array}{c}7 \cdot 1 \\
(3 \cdot 0) \\
2 \cdot 9 \\
(1 \cdot 3) \\
4 \cdot 2 \\
(2 \cdot 8)\end{array}$ & $\begin{array}{c}7 \cdot 1 \\
(3 \cdot 3) \\
3 \cdot 0 \\
(1 \cdot 3) \\
4 \cdot 1 \\
(3 \cdot 1)\end{array}$ & $\begin{array}{c}7 \cdot 1 \\
(3 \cdot 2) \\
2 \cdot 9 \\
(1 \cdot 3) \\
4 \cdot 2 \\
(3 \cdot 1)\end{array}$ & $\begin{array}{c}7 \cdot 2 \\
(3-1) \\
3 \cdot 0 \\
(1-3) \\
4 \cdot 2 \\
(3 \cdot 0)\end{array}$ & $\begin{array}{l}\text { NS } \\
\text { NS } \\
\text { NS }\end{array}$ & $\begin{array}{c}6 \cdot 3 \\
(2 \cdot 3) \\
2 \cdot 4 \\
(1 \cdot 0) \\
3 \cdot 9 \\
(2 \cdot 7)\end{array}$ & $\begin{array}{c}6.4 \\
(3.0) \\
2.5 \\
(1 \cdot 1) \\
3.9 \\
(2 \cdot 8)\end{array}$ & $\begin{array}{c}6.5 \\
(2.9) \\
2.5 \\
(1 \cdot 2) \\
4 \cdot 0 \\
(2 \cdot 7)\end{array}$ & $\begin{array}{c}6 \cdot 6 \\
(3 \cdot 1) \\
2 \cdot 6 \\
(1 \cdot 2) \\
4 \cdot 0 \\
(3 \cdot 0)\end{array}$ & $\begin{array}{c}* \\
(3 \cdot 0) \\
* \\
(3 \cdot 7) \\
\text { NS }\end{array}$ \\
\hline $\begin{array}{l}\% \text { Energy } \\
\text { Total } \\
\text { (SD) } \\
\text { N-tFA } \\
\text { (SD) } \\
\text { H-tFA } \\
\text { (SD) }\end{array}$ & $\begin{array}{l}2.7 \\
(0.86) \\
1.1 \\
(0.35) \\
1.6 \\
(0.94)\end{array}$ & $\begin{array}{c}2.7 \\
(0.94) \\
1.1 \\
(0.39) \\
1.5 \\
(1.04)\end{array}$ & $\begin{array}{c}2 \cdot 8 \\
(0.94) \\
1 \cdot 1 \\
(0.41) \\
1 \cdot 6 \\
(1 \cdot 06)\end{array}$ & $\begin{array}{c}2.8 \\
(0.98) \\
1.2 \\
(0.42) \\
1.7 \\
(1.08)\end{array}$ & $\begin{array}{c}* * * * \\
(12 \cdot 4) \\
* * * \\
(7 \cdot 5) \\
* * \\
(4 \cdot 2)\end{array}$ & $\begin{array}{c}3.2 \\
(1 \cdot 08) \\
1 \cdot 2 \\
(0.43) \\
2 \cdot 0 \\
(1 \cdot 23)\end{array}$ & $\begin{array}{c}3.2 \\
(1.08) \\
1.3 \\
(0.46) \\
1.9 \\
(1.22)\end{array}$ & $\begin{array}{c}3 \cdot 3 \\
(1 \cdot 11) \\
1 \cdot 3 \\
(0.46) \\
2 \cdot 0 \\
(1 \cdot 25)\end{array}$ & $\begin{array}{c}3 \cdot 3 \\
(1 \cdot 08) \\
1 \cdot 3 \\
(0 \cdot 47) \\
2 \cdot 0 \\
(1 \cdot 24)\end{array}$ & $\begin{array}{c}* * * \\
(5 \cdot 5) \\
* * \\
(4 \cdot 4) \\
* \\
(2 \cdot 7)\end{array}$ \\
\hline
\end{tabular}

Total, total trans fatty acids; N-tFA, natural sources of trans fatty acids (primarily ruminant); H-tFA, trans fatty acids formed during hydrogenation of oils.

$\dagger$ Significance of differences by ANOVA ( $F$ values in parentheses) on the transformed variables.

* $P<0.05,{ }^{* *} P<0.01,{ }^{* * *} P<0.001,{ }^{* * *} P<0.0001$.

Table 3. Trans fatty acid intake by smoking group in Scottish adults

(Mean values and standard deviations)

\begin{tabular}{|c|c|c|c|c|c|c|c|c|}
\hline \multirow[b]{2}{*}{$\begin{array}{l}\text { Smoking status... } \\
n \ldots\end{array}$} & \multicolumn{4}{|c|}{ Men } & \multicolumn{4}{|c|}{ Women } \\
\hline & $\begin{array}{c}\text { Current } \\
1927\end{array}$ & $\begin{array}{c}\text { Ex- } \\
1267\end{array}$ & $\begin{array}{c}\text { Never } \\
1144\end{array}$ & $P+$ & $\begin{array}{c}\text { Current } \\
1944\end{array}$ & $\begin{array}{l}\text { Ex- } \\
1052\end{array}$ & $\begin{array}{c}\text { Never } \\
2121\end{array}$ & $P \dagger$ \\
\hline \multicolumn{9}{|l|}{$g / d$} \\
\hline Total & $\begin{array}{c}7 \cdot 3 \\
(3 \cdot 3)\end{array}$ & $\begin{array}{c}7 \cdot 1 \\
(3 \cdot 2)\end{array}$ & $\begin{array}{c}7 \cdot 1 \\
(3 \cdot 0)\end{array}$ & & $\begin{array}{c}6.4 \\
(3.1)\end{array}$ & $\begin{array}{c}6 \cdot 2 \\
(2 \cdot 9)\end{array}$ & $\begin{array}{c}6 \cdot 6 \\
(2.9)\end{array}$ & $\begin{array}{c}* * \\
(8-0)\end{array}$ \\
\hline N-tFA & $\begin{array}{c}(3.5) \\
3 \cdot 2\end{array}$ & $\begin{array}{l}(32) \\
2.8\end{array}$ & $\begin{array}{c}(3.0) \\
2 \cdot 7\end{array}$ & $* * * *$ & 2.7 & $2 \cdot 3$ & $2 \cdot 4$ & ***** \\
\hline (SD) & $(1 \cdot 3)$ & $(1 \cdot 3)$ & $(1 \cdot 2)$ & (63) & $(1 \cdot 2)$ & $(1 \cdot 1)$ & $(1 \cdot 1)$ & (65) \\
\hline H-tFA & $4 \cdot 1$ & $4 \cdot 3$ & $4 \cdot 4$ & $* * * *$ & 3.7 & 3.9 & $4 \cdot 2$ & $* * * *$ \\
\hline (SD) & $(3 \cdot 2)$ & $(3 \cdot 0)$ & $(2 \cdot 8)$ & $(9 \cdot 8)$ & $(2.9)$ & $(2 \cdot 7)$ & $(2 \cdot 7)$ & (31) \\
\hline \multicolumn{9}{|l|}{$\%$ Energy } \\
\hline Total & $2 \cdot 6$ & $2 \cdot 8$ & $2 \cdot 9$ & $* * * *$ & $3 \cdot 2$ & $3 \cdot 2$ & $3 \cdot 4$ & $* * * *$ \\
\hline (SD) & $(0 \cdot 97)$ & $(0.96)$ & $(0.89)$ & (34) & $(1.09)$ & $(1.08)$ & $(1 \cdot 08)$ & $(26)$ \\
\hline N-tFA & $1 \cdot 2$ & $1 \cdot 1$ & $1 \cdot 1$ & $* * *$ & 1.4 & $1 \cdot 2$ & $1 \cdot 2$ & $* * * *$ \\
\hline (SD) & $(0.41)$ & $(0.39)$ & $(0.39)$ & $(7 \cdot 5)$ & $(0.47)$ & $(0 \cdot 45)$ & $(0 \cdot 44)$ & (51) \\
\hline H-tFA & 1.5 & 1.7 & 1.8 & $* * * *$ & 1.8 & $2 \cdot 0$ & $2 \cdot 1$ & $* * * *$ \\
\hline (SD) & $(1.08)$ & $(1.04)$ & $(1 \cdot 00)$ & (49) & $(1 \cdot 26)$ & $(1 \cdot 18)$ & $(1 \cdot 22)$ & (57) \\
\hline
\end{tabular}

Total, total trans fatty acids; N-tFA, natural sources of trans fatty acids (primarily ruminant); H-tFA, trans fatty acids formed during hydrogenation of oils.

$\uparrow$ Significance of differences by ANOVA ( $F$ values in parentheses) on the transformed variables.

$* * \mathrm{P}<0.01, * * * P<0.001, * * * * P<0.0001$. 


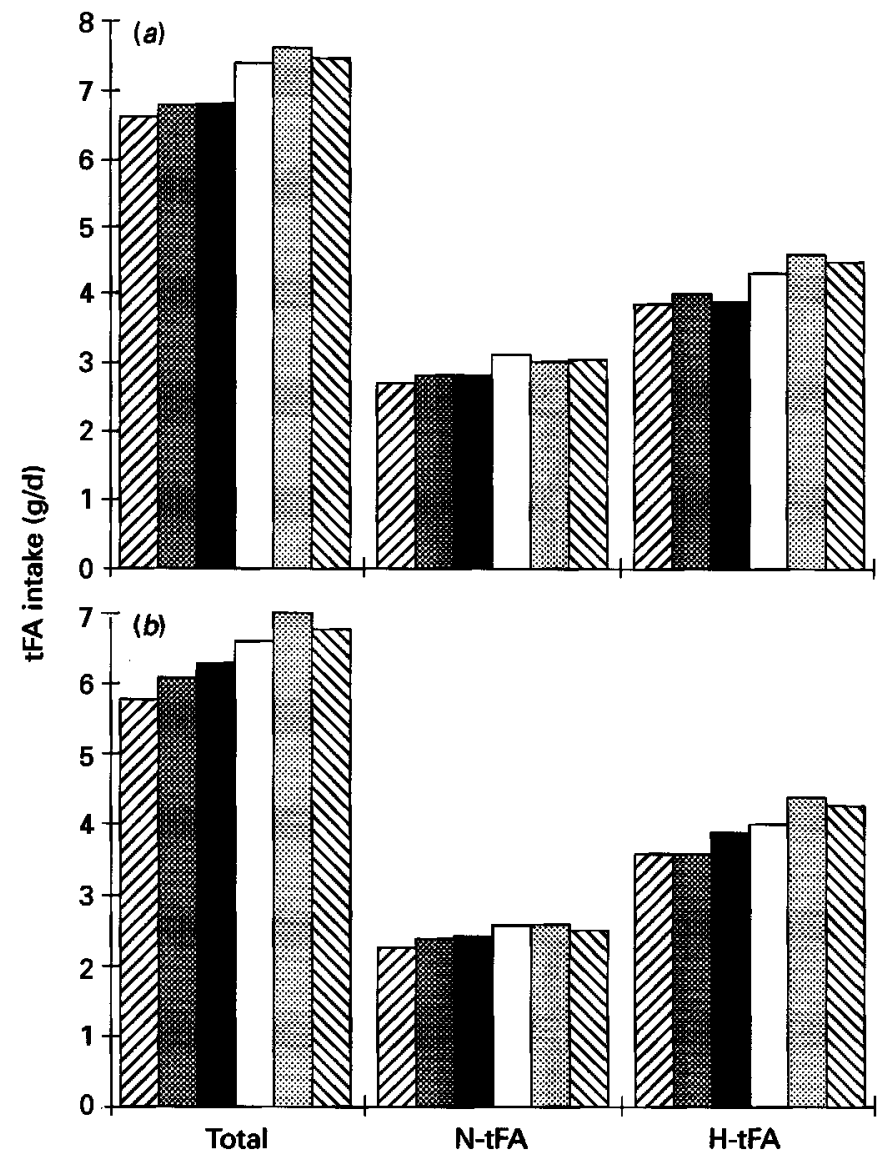

Fig. 1. Trans fatty acid (tFA) intakes $(\mathrm{g} / \mathrm{d})$ in Scottish adult men $(a)$ and women $(b)$ according to social class group. ( $\boxminus)$, Group I; (瑶), group II; ( $\square$ ), group IIIN; ( $\square$ ), group IIIM; (图), group IV; (\$), group V. Total, total tFA; N-tFA, natural sources of tFA (primarily ruminant); H-tFA, tFA formed during hydrogenation of oils. Differences between social class groups were significant (ANOVA, $P<0.001$ ) for each tFA variable for both sexes.

and $2.7 \mathrm{~g} / \mathrm{d}(1.8 \%$ energy) and $11.7 \mathrm{~g} / \mathrm{d}(5.2 \%$ energy) for women. Quantitatively, tFA intake was greater in men than women, but as a percentage of total energy or total fat it was lower in men than women. H-tFA made up nearly $58 \%$ of total $\mathrm{tFA}$ for men and $61 \%$ for women. For men, total, N-tFA and H-tFA correlated significantly (all $P<0.001$ ) with dietary total fat $(r 0.75,0.73$ and 0.39 respectively), with saturated fat $(r 0.64,0.87$ and 0.21 respectively), and with polyunsaturated fat $(r 0.43,-0.15$ and 0.54 respectively). For women the correlation coefficients were very similar, if not identical, to those for men.

tFA intakes by 5 -year age groups are shown in Table 2 . There was no significant difference in intake $(\mathrm{g} / \mathrm{d})$ for men with age, while a small increase in total and $\mathrm{N}$-tFA occurred with age for women $(P<0.05)$. Expressed as a percentage of energy ( $\%$ energy), significant differences occurred in tFA intakes with age for men and for women. However the magnitudes of the differences were small $(0 \cdot 1 \%$ energy) and unlikely to be of biological significance.

Mean tFA intakes for the different smoking groups are reported in Table 3. N-tFA were higher in current than never smokers, and the reverse was true for H-tFA. The differences 

Table 4. Percentage of trans fatty acids from each food group in the diet of Scottish
adults

(Mean values and standard deviations)

\begin{tabular}{|c|c|c|c|c|c|c|c|c|c|c|c|c|}
\hline & \multicolumn{4}{|c|}{ Total } & \multicolumn{4}{|c|}{ H-tFA } & \multicolumn{4}{|c|}{ N-tFA } \\
\hline & \multicolumn{2}{|c|}{ Men } & \multicolumn{2}{|c|}{ Women } & \multicolumn{2}{|c|}{ Men } & \multicolumn{2}{|c|}{ Women } & \multicolumn{2}{|c|}{ Men } & \multicolumn{2}{|c|}{ Women } \\
\hline & Mean & SD & Mean & SD & Mean & SD & Mean & SD & Mean & $\mathrm{SD}$ & Mean & SD \\
\hline Breads & $2 \cdot 2$ & $1 \cdot 7$ & 1.7 & 1.4 & $6 \cdot 4$ & $12 \cdot 0$ & $5 \cdot 0$ & $10 \cdot 0$ & 0 & & 0 & \\
\hline Red meat & 11.8 & $6 \cdot 6$ & $11 \cdot 2$ & 6.7 & 0 & & 0 & & $27 \cdot 4$ & $12 \cdot 4$ & $27 \cdot 2$ & $13 \cdot 1$ \\
\hline Meat products & 3.5 & $3 \cdot 4$ & $2 \cdot 5$ & $2 \cdot 8$ & 0 & & 0 & & $8 \cdot 4$ & $7 \cdot 7$ & $6 \cdot 3$ & 6.8 \\
\hline Puddings* & $31 \cdot 1$ & $15 \cdot 4$ & $34 \cdot 9$ & $15 \cdot 8$ & $59 \cdot 7$ & $27 \cdot 3$ & $64 \cdot 4$ & $27 \cdot 4$ & 0 & & 0 & \\
\hline Milk & $8 \cdot 9$ & $6 \cdot 0$ & 8.4 & $6 \cdot 1$ & 0 & & 0 & & $20 \cdot 6$ & $12 \cdot 2$ & $20 \cdot 3$ & $13 \cdot 1$ \\
\hline Cream & 0.4 & 0.88 & 0.5 & $1 \cdot 10$ & $\mathbf{0}$ & & 0 & & 0.8 & $2 \cdot 0$ & $1 \cdot 1$ & $2 \cdot 4$ \\
\hline Cheese & $5 \cdot 4$ & $4 \cdot 2$ & 6.4 & $5 \cdot 1$ & 0 & & 0 & & $12 \cdot 9$ & $9 \cdot 1$ & $16 \cdot 1$ & $11 \cdot 3$ \\
\hline Butter & $10 \cdot 6$ & $13 \cdot 2$ & $11 \cdot 3$ & $13 \cdot 7$ & 0 & & 0 & & $17 \cdot 6$ & $19 \cdot 5$ & $19 \cdot 4$ & $20 \cdot 7$ \\
\hline PUFA margarines & $4 \cdot 7$ & $11 \cdot 1$ & 4.9 & 11.6 & $7 \cdot 5$ & $18 \cdot 1$ & $7 \cdot 7$ & $1 \cdot 0$ & 0 & & 0 & \\
\hline Other margarines + lard & $15 \cdot 4$ & $21 \cdot 9$ & $14 \cdot 3$ & $21 \cdot 5$ & $21 \cdot 2$ & $30 \cdot 7$ & $19 \cdot 8$ & $29 \cdot 6$ & $2 \cdot 2$ & $3 \cdot 4$ & $1 \cdot 3$ & $2 \cdot 0$ \\
\hline Vegetable oils & $2 \cdot 2$ & $3 \cdot 0$ & $1 \cdot 2$ & 1.6 & $5 \cdot 2$ & $10 \cdot 4$ & $3 \cdot 1$ & $7 \cdot 6$ & 0 & & 0 & \\
\hline Othert & $3 \cdot 4$ & $5 \cdot 2$ & $2 \cdot 2$ & $4 \cdot 1$ & 0 & & 0 & & $9 \cdot 2$ & $10 \cdot 3$ & $7 \cdot 2$ & $9 \cdot 8$ \\
\hline Total & 100 & & 100 & & 100 & & 100 & & 100 & & 100 & \\
\hline Mean t-FA (g/d) & $7 \cdot 1$ & $3 \cdot 1$ & 6.4 & $2 \cdot 9$ & $4 \cdot 1$ & $3 \cdot 0$ & $3 \cdot 9$ & $2 \cdot 8$ & $2 \cdot 9$ & $1 \cdot 3$ & $2 \cdot 5$ & $1 \cdot 1$ \\
\hline
\end{tabular}

Total, total trans fatty acids; N-tFA, natural sources of trans fatty acids (primarily ruminant); H-tFA, trans fatty acids formed during hydrogenation of oils; PUFA, polyunsaturated fat.

* Including cakes and biscuits of all types.

$\dagger$ 'Other' foods supplying trans fatty acids are fish, poultry, eggs and potatoes.

between the groups (up to $0.5 \mathrm{~g} / \mathrm{d}$ or $0.3 \%$ energy) were statistically significant $(P<0.01)$ for all except total $\mathrm{tFA}$ for men, and represented a variation of $12-15 \%$.

Fig. 1 presents the mean t-FA intakes $(\mathrm{g} / \mathrm{d})$ by occupational social class. Total, $\mathrm{N}-$ and H-tFA intakes were higher in the lower social class groups, IIIM-V $(P<0.001$ for all). When expressed as \% energy the significant differences between the social class group persisted for women but were lost for men (results not shown).

Table 4 shows the nutrient source data for the total and component tFA by sex. The 'pudding' group of foods (including all cakes, biscuits and sweets) was the largest provider of total tFA (and also of H-tFA) followed by other margarines ( + lard), red meat, butter and milk. The 'puddings' group provided about $60 \%$ of the dietary intake of $\mathrm{H}$ tFA, with approximately $20 \%$ coming from other margarines. $\mathrm{N}$-tFA came predominantly from ruminant meat ( $27 \%$ of total), followed by milk and butter $(20 \%)$ and cheese at $13 \%$ for men and $16 \%$ for women. The sex difference in the contribution of cheese to N-tFA intakes was made up by more coming from the meat products and 'other foods' group for men than for women.

\section{DISCUSSION}

In order to discuss these tFA results in relation to previous reports, the methods of assessment need comparison between studies. These data are based on a FFQ, and these, in general, are able to estimate nutrient intakes (to varying degrees of adequacy) in populations. The validity and results derived from this FFQ have been widely reported (e.g. Bolton-Smith et al. $1991 a-c)$, although specific validation of tFA has not been possible. The tFA data which were incorporated into this FFQ came from a range of sources 
including 'confidential' and published values for individual products, and the food group values used in the Total Diet Study (courtesy of MAFF) as appropriate. Hence the 'average' tFA value which was assigned to each food question on the FFQ was generally the mean of several estimates from different sources. Wherever possible (e.g. for branded margarines) the tFA value pertaining to the mid 1980s was used in preference to more upto-date values. This is particularly pertinent when the large shift in types of oils used for margarine manufacture over the last 10 years is considered. In 1982 fish oil made up $43 \%$ of the oil used in the manufacture of margarines, and animal fat $13.7 \%$. By 1992 these values were respectively $21.8 \%$ and $6.0 \%$ (from MAFF production figures for margarines and table spreads). The shift from hydrogenated fish oil to hydrogenated seed oils will have reduced the tFA content of margarines in general, while the reduction in the use of animal fats will have increased the potential for H-tFA in margarines.

An estimate of tFA intake based on the National Food Survey data (Burt \& Buss, 1984) in the early $1980 \mathrm{~s}$ produced a value of $7 \mathrm{~g} / \mathrm{d}$ (men and women combined) and calculations based on possible extremes of intakes by these authors suggested a range of 5-27 $\mathrm{g} / \mathrm{d}$. Their average value is remarkably similar to that of $7 \cdot 1 \mathrm{~g} / \mathrm{d}$ for men and $6.4 \mathrm{~g} / \mathrm{d}$ for women reported in this Scottish population; however, a greater range of intake appears possible $(1-48 \mathrm{~g} / \mathrm{d})$.

In the only other population estimate of tFA levels in the UK diet (Gregory et al. 1990), intake was assessed by $7 \mathrm{~d}$ weighed records during 1986-7. While this is considered to be the most accurate method for determining intake of individuals, this can only improve the accuracy of population estimates if the nutrient values exist for all the individual foods recorded. Since such complete information on tFA is not available, the tFA intakes will have been culled from estimated and average values in a similar manner to that reported here. The lower mean intakes reported in The Dietary and Nutritional Survey of British Adults (Adult Survey) (5.6 and $4.0 \mathrm{~g} / \mathrm{d}$ for men and women respectively compared with $7 \cdot 1$ and $6.4 \mathrm{~g} / \mathrm{d}$ ) may be partly accounted for by the high degree of 'under-reporting' (Pryer et al. 1994) which tends to be characteristic of weighed-record methodologies (Black et al. 1991). The range of intakes was also lower (men 1-21 g/d; women 1-14 g/d; MAFF, 1994b) than in the SHHS population.

It is interesting that the approximated H-tFA/N-tFA split in the Adult Survey was $51 / 49 \%$ for men and women, whereas that estimated from the National Food Survey data (Burt \& Buss, 1984) was 57/43, and the values for the SHHS population were 58/42 for men and 61/39 for women. The SHHS values are nearer to those of 60/40 reported for American women in 1980 (Willett et al. 1993).

Reported mean intakes of tFA in the USA vary greatly depending on the method of assessment. A semi-quantitative FFQ has consistently provided estimates of about $4 \mathrm{~g} / \mathrm{d}$ in surveys of men and women between 1980 and 1990 (Troisi et al. 1992; Willett et al. 1993; Ascherio et al. 1994). In contrast, per capita intake calculations by Hunter and Applewhite in 1984 (Hunter \& Applewhite, 1986) and 1989 (Hunter \& Applewhite, 1991) suggest intakes of 7.6 and $8.3 \mathrm{~g} / \mathrm{d}$ respectively. However, different per capita calculations by Enig et al. (1990) 're-evaluated' previous estimates up to a mean of $13.3 \mathrm{~g} / \mathrm{d}$, with a range of $1.6-38.7 \mathrm{~g} / \mathrm{d}$. Clearly, with such disagreement of mean intakes from the same per capita data in the USA, it is difficult to judge how tFA intakes in America compare with the UK figures. Although hydrogenated vegetable oils are widely used in the USA, hydrogenated fish oils are virtually absent from the US diet (British Nutrition Foundation, 1987). In contrast, fish oils were widely used in the UK in the mid $1980 \mathrm{~s}$, and thus it may be reasonable to expect mean US intakes to be less than those of the UK. As such, the values reported by Willett and colleagues from FFQ data could be the most appropriate, although the range of intakes reported by Enig et al. (1990) is feasible. Estimates of mean tFA intakes 
from other countries include $5 \mathrm{~g} / \mathrm{d}$ in Sweden (Akesson et al. 1981), $6.5 \mathrm{~g} / \mathrm{d}$ in Israel (Enig et al. 1984) and $2.4 \mathrm{~g} / \mathrm{d}$ in Spain (Boatella et al. 1993).

Regarding the tFA intakes in subgroups of the SHHS population, the differences between groups were frequently significant but they were not large. Taken in isolation these differences may not be important; however, in conjunction with low linoleic acid intakes, for example in the manual social class groups, they may take on biological significance (Wahle \& James, 1993). The difference in tFA intake between the social class groups may be due to the higher proportion of fat which comes from hard margarines and meat products (e.g. sausages, pies) in the manual compared with the non-manual groups (Bolton-Smith et al. 1991a). The Adult Survey (Gregory et al. 1990; MAFF, 1994b) reported no significant differences in tFA intakes between age, social class or regional groups but did find significantly higher intakes in those receiving benefits and in women with partners and dependants compared with lone mothers.

The differences in tFA intakes between the smoking groups appear to indicate that the potential coronary risk from $\mathrm{H}$-tFA acts in the opposite direction compared with most other aspects of smoking. Nutrient source data (unpublished results) indicate that this may be due to a higher consumption of animal fats from spreads and meat products in smokers than non-smokers. Interestingly, the same pattern of higher N-tFA and lower H-tFA in smokers was reported by Willett et al. (1993) for American women.

The upper limits of tFA intake recommended by the Department of Health (1991) and the Scottish Office Home and Health Department (1993) of $5 \mathrm{~g} / \mathrm{d}$ or $2 \%$ energy are presumably based on the results of the Adult Survey. Clearly the SHHS population mean is greater than this, and $5 \%$ of men and women consumed more than 12.7 and $11.7 \mathrm{~g} / \mathrm{d}$ respectively. The need for recommending upper limits may be particularly important in populations which have low linoleic acid intakes (such as the Scots) due to the ability of certain tFA (primarily elaidic) to impede essential fatty acid metabolism. Since tFA are reported to alter the LDL:HDL-cholesterol ratio unfavourably, they would also be contraindicated in groups, such as the Scots, which are at high risk of CHD. If the reported link between CHD and H-tFA intake (Willett et al. 1993) is confirmed, then maybe the recommendations should be specific for dietary H-tFA and not total tFA. However, we do not yet have sufficient information on which to base such a decision. The most recent reports of adipose tissue tFA levels in relation to sudden cardiac death (Roberts et al. 1995) and myocardial infarction (Aro et al. 1995) appear only to complicate the issue further, and an additional analysis of tFA intake and prevalent CHD from the SHHS data-set (BoltonSmith et al. 1995) is by no means conclusive.

Further population assessments of tFA intakes are clearly needed in the 1990s since the National Food Survey data (MAFF, 1992) demonstrate a disproportionate decline in intake of fat from milk and milk products (39\%) compared with total fat (18\%) between 1981 and 1991. While this may have given rise to an increase in the H-tFA:N-tFA ratio over this period, the current situation is unclear since recent trends suggest a greater relative decline in margarine consumption than in milk-derived fats between 1991 and 1993 (MAFF, 1994a) and intake of vegetable oils is still increasing. Either way, the situation deserves monitoring particularly with regard to the health of vulnerable groups.

Although adherence to the current guidelines for an overall reduction in fat intake will also have the effect of reducing dietary tFA, given the increasing publicity regarding the potential harm from tFA, individuals may actively try to reduce their H-tFA intakes. From this public health perspective it is interesting that the proportion of H-tFA intake which may be most amenable to direct modification by an individual (i.e. that from spreading fats) makes up less than a third of total intake. The majority of H-tFA enter the diet as 'hidden' fat in cakes and biscuits (very few of these are made only with butter or pure oils). Thus 
if further scientific evidence does support a need to reduce tFA intake from hydrogenated vegetable and fish oils, support from the cake and biscuit manufacturers would be required since only a limited reduction could be achieved by a shift in use from high $\mathrm{H}$-tFA margarines to dairy and other equivalent low H-tFA spreads.

Financial support is acknowledged from the Scottish Office Home and Health Department who funded the Scottish Heart Health Study, and the Butter Council who funded S.F.

\section{REFERENCES}

Akesson, B., Johansson, B. M., Suensson, M. \& Ockersman, A. (1981). Content of trans-octadecenoic acid in vegetarian and normal diets in Sweden, analysed by duplicate portion technique. American Journal of Clinical Nutrition 34, 2517-2520.

Aro, A., Lardinaal, A. F. M., Salminen, I., Kark, J. D., Riemersma, R. A., Delgado-Rodriguez, M., GomezAracena, J., Huttunen, J. K., Kohlmeier, L., Martin, B. C., Martin-Moreno, J. M., Mazaev, V. P., Ringstad, J., Thamm, M., van't Veer, P. \& Kok, F. J. (1995). Adipose tissue isomeric trans fatty acids and risk of myocardial infarction in nine countries: the EURAMIC study. Lancet 345, 273-278.

Ascherio, A., Hennekins, C. H., Buring, J. E., Master, C., Stampfer, M. J. \& Willett, W. C. (1994). Trans fatty acid intake and risk of myocardial infarction. Circulation 89, 94-101.

Black, A. E., Goldberg, G. R., Jebb, S. A., Livingstone, M. B. E., Cole, T. J. \& Prentice, A. M. (1991). Critical evaluation of energy intake data using fundamental principles of energy physiology. 2. Evaluating the results of published surveys. European Journal of Clinical Nutrition 45, 583-599.

Boatella, J., Rafecas, M. \& Codoney, R. (1993). Isomeric trans fatty acids in the Spanish diet and their relationships with changes in fat intake pattern. European Journal of Clinical Nutrition 47, Suppl. 1, S62-S65.

Bolton-Smith, C., Brown, C. A. \& Tunstall-Pedoe, H. (1991a). Nutrient sources in non-manual and manual occupational groups. Results from the Scottish Heart Health Study. Journal of Human Nutrition and Dietetics 4, 291-306.

Bolton-Smith, C., Casey, C. E., Gey, K. F., Smith, W. C. S. \& Tunstall-Pedoe, H. (1991 b). Antioxidant vitamin intakes assessed using a food-frequency questionnaire: correlation with biochemical status in smokers and nonsmokers. British Journal of Nutrition 65, 337-346.

Bolton-Smith, C., Smith, W. C. S., Woodward, M. \& Tunstall-Pedoe, H. (1991 c). Nutrient intakes of different social class groups: results from the Scottish Heart Health Study. British Journal of Nutrition 65, 321-335.

Bolton-Smith, C., Woodward, M., Fenton, S. \& Brown, C. A. (1995). Does dietary trans-fatty acid intake relate to prevalence of heart disease in Scotland? European Heart Journal (In the Press).

Bolton-Smith, C., Woodward, M., Tavendale, R. \& Tunstall-Pedoe, H. (1992a). Adipose tissue fatty acids: risk factors for CHD? Proceedings of the Nutrition Society 51, 139A.

Bolton-Smith, C., Woodward, M. \& Tunstall-Pedoe, H. (1992b). Smoking, and correlations between dietary fat and adipose tissue linoleate $(18: 2 n-6)$ using a food-frequency questionnaire. Proceedings of the Nutrition Society 52, 26A.

British Nutrition Foundation (1987). Task Force Report on Trans Fatty Acids, London: BNF.

Burt, R. \& Buss, D. H. (1984). Dietary fatty acids in the UK. British Journal of Clinical Practice 38, S20-S21.

Department of Health (1991). Dietary Reference Values for Food Energy and Nutrients for the United Kingdom. Report on Health and Social Subjects no. 41. London: H.M. Stationery Office.

Enig, M. G., Atal, S., Keeney, M. \& Sampugna, J. (1990). Isomeric trans fatty acids in the United States diet. Journal of the American College of Nutrition 9, 471-486.

Enig, M. G., Budowskie, P. \& Blondheim, S. H. (1984). Trans unsaturated fatty acids in margarines and human subcutaneous fat in Israel. Human Nutrition: Clinical Nutrition 38C, 223-230.

Federation of American Societies for Experimental Biology (1985). Health Aspects of Dietary Trans Fatty Acids. Bethesda, MD: FASEB.

Gregory, J., Foster, K., Tyler, H. \& Wiseman, M. (1990). The Dietary and Nutritional Survey of British Adults. London: H.M. Stationery Office.

Hunter, J. E. \& Applewhite, T. H. (1986). Isomeric fatty acids in the United States diet-levels and health perspectives. American Journal of Clinical Nutrition 44, 707-717.

Hunter, J. E. \& Applewhite, T. H. (1991). Reassessment of trans fatty acids availability in the United States diet. American Journal of Clinical Nutrition 54, 303-369.

Judd, J. T., Cleavidance, B. A., Muesing, R. A., Sunkin, M. E. \& Podczasky, J. J. (1994). Dietary trans fatty acids: effects of plasma lipids and lipoproteins in healthy men and women. American Journal of Clinical Nutrition 59, 861-868.

Lichtenstein, A., Ausman, L. M., Carrasco, W., Jenner, J. L. \& Ordovas, J. M. (1993). Hydrogenation impairs the hypolipidemic effect of corn oil in humans. Arteriosclerosis Thrombosis 13, 154-161.

Mensink, R. D. \& Katan, M. B. (1990). Effect of trans fatty acids on HDL and LDL cholesterol levels in healthy subjects. New England Journal of Medicine 323, 439-445. 
Ministry of Agriculture, Fisheries and Food (1992). Household Food Consumption and Expenditure 1991. London: H.M. Stationery Office.

Ministry of Agriculture, Fisheries and Food (1994a). National Food Survey 1993. London: H.M. Stationery Office.

Ministry of Agriculture, Fisheries and Food (1994b). The Dietary and Nutritional Survey of British Adults: Further Analysis. London: H.M. Stationery Office.

Office of Population Censuses and Surveys (1980). Classification of Occupation. London: H.M. Stationery Office.

Paul, A. A. \& Southgate, D. A. T. (1978). McCance and Widdowson's The Composition of Foods. London: H.M. Stationery Office.

Peacock, L. I. L. \& Wahle, K. W. J. (1988). Isomeric cis and trans fatty acids and porcine reactivity to collagen in vitro. Biochemical Society Transactions 16, 21.

Pryer, J. A., Vrijheid, M., Nichols, R. \& Elliott, P. (1994). Who are the 'low energy reporters' in the Dietary and Nutritional Survey of British Adults? Proceedings of the Nutrition Society 53, 235A.

Riemersma, R. A., Wood, D. A., Butler, S., Elton, R. A., Oliver, M., Salo, M., Nikkari, T., Vartiaineen, E., Puiska, P., Gey, F., Rubba, P., Mancini, M. \& Fidanza, F. (1986). Linoleic acid content in adipose tissue and coronary heart disease. British Medical Journal 292, 1423-1427.

Roberts, T. L., Wood, D. A., Riemersma, R. A., Gallagher, P. J. \& Lampe, F. C. (1995). Trans isomers of oleic and linoleic acids in adipose tissue and sudden cardiac death. Lancet 345, 278-282.

Scottish Office Home and Health Department (1993). The Scottish Diet: Report of a Working Party to the Chief Medical Officers of Scotland. Edinburgh: The Scottish Office.

Smith, W. C. S., Tunstall-Pedoe, H., Crombie, I. K. \& Tavendale, R. (1989). Concomitants of excess coronary deaths - major risk factors and lifestyle findings from 10359 men and women in the Scottish Heart Health Study. Scottish Medical Journal 34, 550-555.

Troisi, R., Willett, W. C. \& Weiss, S. T. (1992). Trans fatty acid intake in relation to serum lipid concentrations in adult men. American Journal of Clinical Nutrition 56, 1019-1024.

Wahle, K. W. J. \& James, W. P. T. (1993). Isomeric fatty acids and human health. European Journal of Clinical Nutrition 47, 828-839.

Wahle, K. W. J., McIntosh, G., Duncan, W. R. H. \& James, W. P. T. (1991). Concentrations of linoleic acid in adipose tissue differ with age in women but not men. European Journal of Clinical Nutrition 45, $195-202$.

Willett, W. C., Stampfer, M. J., Manson, J. E., Colditz, G. A., Speizer, F. E., Rosner, B. A., Sampson, L. A. \& Hennikins, C. H. (1993). Incidence of trans fatty acids and risk of coronary heart disease among women. Lancet $341,581-585$. 